\title{
Adult hypophosphatasia
}

INSERM

\section{Source}

INSERM. (1999). Orphanet: an online rare disease and orphan drug data base. Adult hypophosphatasia. ORPHA:247676

Adult hypophosphatasia (A-HPP) is a mildform of hypophosphatasia (see this term) characterized by osteomalacia,chondrocalcinosis, osteoarthropathy, stress fractures during middle age, and dental anomalies. 